\title{
Sulfate metabolism in the alloxan-diabetic rat: relationship of altered sulfate pools to proteoglycan sulfation in heart and other tissues
}

\author{
M.J.Spiro \\ Elliott P. Joslin Research Laboratory, Joslin Diabetes Center, and the Department of Medicine, Harvard Medical School, Boston, \\ Massachusetts, USA
}

\begin{abstract}
Summary. The incorporation of $\left[{ }^{35} \mathrm{~S}\right] \mathrm{sulfate}$ into heart proteoglycans has been studied in normal and alloxan-diabetic rats by perfusion and in vivo administration of the isotope; in the latter situation, comparison was also made of radiolabeled sulfate utilization by several other tissues (kidney, liver, lung, muscle, testes and skin). The radiolabeled products were characterized by sodium dodecylsulfate polyacrylamide gel electrophoresis and anion exchange chromatography, as well as by sizing of the glycosaminoglycan chains by gel filtration both before and after nitrous acid treatment. The most prominent band observed in the heart guanidine extract by electrophoresis had a molecular weight of 85,000 and minor components $\left(M_{r}=360,000\right.$ and 170,000$)$ were also detected; approximately $20 \%$ of the proteoglycan associated $\left[{ }^{35} \mathrm{~S}\right] \mathrm{sul}-$ fate was present in heparan sulfate chains. After perfusion the pattern, as well as the amount of radioactivity recovered from the diabetic heart, was similar to the normal heart. In contrast, after intraperitoneal injection of the $\left[{ }^{35}\right.$ S]sulfate, a substantial reduction in incorporation was found not only in heart but in several other tissues studied, although no qualitative differences were noted in the macromolecules formed by the two groups of animals. Measurement of the serum sul-
\end{abstract}

fate concentration indicated that the level in the alloxan-diabetic rat $(1.23 \mathrm{mmol} / \mathrm{l})$ was significantly less $(p<0.01)$ than that of the normal rat $(1.67 \mathrm{mmol} / \mathrm{l})$. Moreover, when serum specific activity curves were prepared between $10 \mathrm{~min}$ and $24 \mathrm{~h}$ after isotope injection, the decline in the diabetic curve was found to be much more rapid than that of the normal curve, with the area under the diabetic specific activity curve between 0 and $4 \mathrm{~h}$ being 0.61 that of normal $(p<0.005)$. Since the amount of free $\left.{ }^{35} \mathrm{~S}\right]$ sulfate recovered in the tissues was also considerably lower in the diabetic animals, the specific activity differences of the precursor appear to account for the reduced incorporation of sulfate observed in vivo in contrast to perfusion, where pool sizes and specific activity can be controlled. Measurement of renal sulfate clearance indicated that it is enhanced in the alloxan-diabetic rats, suggesting that handling of sulfate in diabetes is similar to that previously described in this disease for inorganic phosphate.

Key words: Serum sulfate, tissue sulfate, heart proteoglycans, kidney proteoglycans, heparan sulfate, renal sulfate clearance.
Although most of the attention given to the long-term effects of diabetes mellitus has focused on the microangiopathy affecting the kidneys and eyes, investigations carried out over the past decade have indicated that similar changes take place in a number of other tissues. In particular, a correlation has been made between the occurrence of glomerulosclerosis in the kidney and the accumulation in the heart of periodic acidSchiff reactive material surrounding muscle fibers and small blood vessels [1]; since functional changes not attributable to coronary artery disease were also observed in these patients, this condition has been termed diabetic cardiomyopathy [2-4].

While the primary causes of the extracellular matrix changes affecting the microvasculature in diabetes are still incompletely understood, the alterations which occur have been examined in greatest detail for the glomerular basement membrane, which undergoes thickening and a loss of selective permeability [5, 6]. One factor responsible for the abnormal nature of this membrane in diabetes appears to be the development of an imbalance among its constituents, which is reflected in the reduced levels of laminin and proteoglycan [7] as well as in the presence of excessive amounts of collagen observed in the membrane itself [9] and in the intact glomerulus $[9,10]$. Indeed, the suggestion has been made on the basis of $\left[{ }^{35} S\right]$ sulfate incorporation studies using a basement membrane producing tumour that impaired proteoglycan synthesis followed by a compensatory collagen overproduction may be an im- 
portant aspect in the development of the diabetic derangement [11].

While the heparan sulfate proteoglycan of the kidney basement membrane is believed to play an important role as a component of the glomerular filtration barrier [12], myocardial proteoglycans may serve equally vital functions, particularly in the capacity of a calcium reservoir [13], by virtue of their large number of negatively charged residues. Any abnormality occurring in these components in the heart as a consequence of the metabolic derangement would therefore have serious consequences for this organ.

Several studies have indicated the usefulness of the rat as a model for diabetic cardiomyopathy. When diabetes is induced in these animals by injection of streptozotocin, functional changes take place in the cardiac myocytes which are reversible by insulin administration [14]. Myocardial capillary basement membrane thickness has been shown to increase with age more rapidly in rats with diabetes [15]; in another study, poorly controlled diabetic animals were found to have significantly more myocardial connective tissue than animals given sufficient insulin to maintain them in a well-controlled state [16].

In the present study, as part of an effort to elucidate the nature and causes of the changes characteristic of diabetic cardiomyopathy, an investigation was undertaken to explore the effect of alloxan diabetes on the synthesis of cardiac proteoglycans in rats. This was evaluated from the incorporation of $\left[{ }^{35} \mathrm{~S}\right]$ sulfate into these macromolecules during heart perfusion as well as after in vivo administration of this isotope; in the latter experiments cardiac sulfate uptake was compared with that of several other tissues of normal and diabetic animals. The influence of the alloxan diabetes on the level and turnover of serum and tissue inorganic sulfate was also determined.

\section{Materials and methods}

\section{Animals}

Male rats (CD strain) obtained from Charles River Laboratories (Wilmington, Mass, USA) were randomly selected for intrafemoral injection of $37 \mathrm{mg} / \mathrm{kg}$ body weight of alloxan monohydrate (Eastman Kodak Co., Rochester, NY, USA) while the remainder of the age-matched animals were kept as controls; all had free access to food. Blood sugar values were determined with the use of the Glucose Analyzer (Beckman, Palo Alto, Calif, USA) and experiments were conducted approximately 6 weeks after the alloxan treatment.

\section{Heart perfusion}

Normal and diabetic rats were anaesthetized with $80 \mathrm{mg} / \mathrm{kg}$ body weight of Nembutal (Abbott Laboratories, N.Chicago, Ill, USA); hearts were pretreated in situ by injection into the right atria of $100 \mathrm{U}$ of Panheprin (Abbott) to prevent clotting and were then removed and attached to the cannula of a Langendorff heart perfusion apparatus [17] maintained at $37^{\circ} \mathrm{C}$. After preliminary treatment for a period of approximately 5 min with a medium consisting of modi- fied Krebs-Henseleit bicarbonate, $\mathrm{pH} 7.4$ [17], containing $2 \mathrm{mmol} / 1$ sodium pyruvate, $5 \mathrm{mmol} / \mathrm{l}$ glucose and Eagle's amino acids [18], which served to initiate beating and remove blood from the organ, perfusion was begun with fresh medium containing in addition $(0.5 \mathrm{mmol} / 1$ sodium oleate, $15 \mathrm{~g} / 1$ of fatty acid-free bovine serum albumin (Sigma Chemical Co. St. Louis, Mo, USA), and sodium $\left[{ }^{35}\right.$ S]sulfate (New England Nuclear Corp., Boston, Mass, USA) of varying specific activities, as indicated for each experiment. At the end of $60 \mathrm{~min}$, the cannula was removed from the apparatus and attached to a syringe containing cold $0.15 \mathrm{~mol} / 1 \mathrm{NaCl}$ which was used to flush the radioactive medium from the heart prior to its being frozen on dry ice.

\section{In vivo ${ }^{35}$ S]sulfate administration}

Age-matched normal and diabetic animals each received $1 \mathrm{mCi}$ of sodium $\left.{ }^{35} \mathrm{~S}\right]$ sulfate, administered intraperitoneally in $0.15 \mathrm{~mol} / 1$ $\mathrm{NaCl}$, either 4 or $24 \mathrm{~h}$ prior to the planned termination of the experiment. Tail vein blood samples were collected in heparinized tubes at several time points, starting at $10 \mathrm{~min}$. At the end of the period specified for isotope incorporation, the animals were anaesthetized with Nembutal and a nonheparinized blood sample of approximately $2 \mathrm{ml}$ was collected from the tail. After opening the abdominal and chest cavities, perfusion with $0.15 \mathrm{~mol} / 1 \mathrm{NaCl}$ at $25^{\circ} \mathrm{C}$ was begun into the left ventricle and continued until the fluid emerging from the cut left atrium became clear. Organs were removed, frozen with dry ice and stored at $-70^{\circ} \mathrm{C}$ until processed.

\section{Treatment of tissues}

Hearts from perfusion experiments were minced finely and disrupted in $4 \mathrm{~mol} / 1$ Sodium chloride by two 5 -s treatments with a Polytron ST10 homogenizer (Brinkmann Instruments, Westbury, NY, USA) at a setting of 6; in this and subsequent extraction steps, the insoluble fraction was removed by centrifugation in a Beckman L5-65 instrument at $100,000 \mathrm{~g}$ for $45 \mathrm{~min}$. After a wash with $50 \mathrm{mmol} / \mathrm{l}$ Tris-acetate, $\mathrm{pH} 7.4$, the pellet was further extracted with $0.6 \mathrm{~mol} / 1 \mathrm{KCl}$. Tissues from the in vivo experiments were treated instead with two Tris-acetate extractions, followed by $2 \mathrm{~mol} / 1 \mathrm{KCl}$. In both cases, these three extractions served to remove essentially all of the small molecular weight sulfate-labeled components. The insoluble residue was then treated with $1 \%(\mathrm{v} / \mathrm{v})$ Triton X-100 (Fisher Scientific Co., Fair Lawn, NJ, USA) containing $2 \mathrm{mmol} / 1$ phenylmethylsulfonyl fluoride (Behring Diagnostics, San Diego, Calif, USA) and $0.4 \mathrm{mg} /$ $\mathrm{ml}$ of deoxyribonuclease (Sigma) for $1 \mathrm{~h}$ at $2^{\circ} \mathrm{C}$; after centrifugation further extraction of the pellet was performed for $1 \mathrm{~h}$ at room temperature with $4.5 \mathrm{~mol} / 1$ guanidine hydrochloride (Sigma) containing a mix of protease inhibitors $(1 \mathrm{mmol} / 1$ benzamidine, phenylmethylsulfonyl fluoride and EDTA, $2.5 \mathrm{mmol} / 1 \mathrm{~N}$-ethylmaleimide, and $10 \mu \mathrm{mol} / 1 \mathrm{p}$-chloromercuribenzoate (all from Sigma). The final extraction step consisted of incubating the guanidine-insoluble material with $40 \mathrm{~g} / 1$ sodium dodecylsulfate (SDS)-50 ml/1 2-mercaptoethanol (Fisher) at $100^{\circ} \mathrm{C}$ for $5 \mathrm{~min}$, followed by treatment at $37^{\circ} \mathrm{C}$ for $2 \mathrm{~h}$ and centrifugation at $2000 \mathrm{~g}$ for $20 \mathrm{~min}$ at room temperature.

The amount of radioactivity incorporated into the $\mathrm{NaCl}$, Trisacetate and $\mathrm{KCl}$ extractable material was determined after precipitation and washing with $80 \mathrm{~g} / 1$ trichloroacetic acid (TCA), followed by solubilization of the pellets in $40 \mathrm{~g} / 1$ SDS- $50 \mathrm{ml} / 1$ 2-mercaptoethanol with heating; aliquots of the Triton, guanidine and SDS extracts were taken directly for scintillation counting.

\section{Measurement of sulfate specific activity}

For the chemical determination of sulfate in blood and tissues, the ultramicro method of Spencer [19], measuring the absorption of benzidine at $248 \mathrm{~nm}$, was employed. Sera obtained from nonheparinized blood collected at the termination of the experiment were treated with TCA at a final concentration of $100 \mathrm{~g} / 1$, and analyses were performed directly on these TCA supernatants. For each tissue the TCA 
supernatant prepared from the first extract was treated with ethyl ether to remove the TCA, and aliquots were then passed through $1 \mathrm{ml}$ columns of Dowex 50-X4 (Bio-Rad, Richmond, Calif, USA). The effluent and wash were then concentrated to dryness prior to analysis. Sulfate standards and blank samples were run through the entire procedure.

Plasma from the heparinized blood samples collected at multiple times during the experiment was also treated with TCA $60 \mathrm{~g} / 1$ final concentration) and radioactivity measurements were made on all of the TCA supernatants by scintillation counting. The areas under the serum specific activity curves were determined by planimetry.

\section{Measurement of renal sulfate clearance}

Radiolabeled sodium sulfate $(200 \mu \mathrm{Ci})$ was administered intraperitoneally in $0.5 \mathrm{ml}$ of sterile isotonic saline to three normal and four alloxan-diabetic rats which were kept in metabolism cages. Tail vein blood was collected at 15 and $30 \mathrm{~min}$ and at 1,2 and $6 \mathrm{~h}$; urine was collected over this time period. From the average radioactivity present per $\mathrm{ml}$ of blood and the total radioactivity collected in the urine, the sulfate clearance $\left(\mathrm{ml} \cdot \mathrm{min}^{-1} \cdot \mathrm{kg}^{-1}\right)$ was calculated.

\section{Characterization of radiolabeled products}

The nature of the $\left[{ }^{35}\right.$ S $]$ sulfate-labeled products was evaluated by SDS-polyacrylamide gel electrophoresis and anion exchange chromatography; the carbohydrate chains released from pronase-prepared glycopeptides by alkaline borohydride were sized by gel filtration both before and after nitrous acid treatment.

Samples were prepared for SDS polyacrylamide electrophoresis by lyophilization followed by extraction with $800 \mathrm{ml} / 1$ ethanol to remove the salt, Triton, guanidine or SDS with which they had been extracted. They were solubilized by heating $5 \mathrm{~min}$ at $100^{\circ} \mathrm{C}$ in $40 \mathrm{~g} / 1$ SDS-50 ml/1 2-mercaptoethanol and run on gradients of 40 to $120 \mathrm{~g} / \mathrm{l}$ acrylamide in the buffer system of Laemmli [20].

Anion exchange chromatography was performed on columns $1 \mathrm{~cm}$ in diameter containing $18 \mathrm{ml}$ of packed Whatman DE-52 (Fisher) prewashed with $50 \mathrm{mmol} / 1$ Tris-chloride in $8 \mathrm{~mol} / \mathrm{l}$ urea. The samples were extensively dialyzed against the buffered urea solution and applied to the columns, which were then washed with $30 \mathrm{ml}$ of the urea and eluted with a gradient of $120 \mathrm{ml}$ of $50 \mathrm{mmol} / 1$ Trischloride and $120 \mathrm{ml}$ of $50 \mathrm{mmol} / 1$ Tris-chloride- $0.7 \mathrm{~mol} / 1 \mathrm{NaCl}$, both containing $8 \mathrm{~mol} / 1$ urea. The salt gradient was monitored with the use of a conductivity meter (Radiometer, Copenhagen, Denmark) and radioactivity was measured by scintillation counting.

For the preparation of glycopeptides, pronase digestion was performed for $72 \mathrm{~h}$ at $37^{\circ} \mathrm{C}$ on dialyzed and lyophilized guanidine extracts resuspended in $0.1 \mathrm{~mol} / 1$ Tris acetate, $\mathrm{pH} 7.8,15 \mathrm{mmol} / 1 \mathrm{cal}-$ cium acetate. Digestion was terminated by boiling and aliquots were analyzed by filtration on Bio-Gel P-30 columns (Bio-Rad) $0.6 \times 140 \mathrm{~cm}$, in $0.5 \mathrm{~mol} / 1$ ammonium bicarbonate, $\mathrm{pH} 7.8$. Buffers were pumped through the gel filtration columns at a rate of $10 \mathrm{ml} / \mathrm{h}$, and the pressure was maintained at approximately 50 psi by an inline pressure relief valve; $0.5 \mathrm{ml}$ fractions were collected and the void $\left(\mathrm{V}_{\mathrm{o}}\right)$ and total $\left(\mathrm{V}_{\mathrm{t}}\right)$ volumes of the columns were determined with the use of Blue Dextran (Pharmacia, Piscataway, NJ, USA) and $\left[{ }^{3} \mathrm{H}\right]$ mannose (New England Nuclear, Boston, Mass, USA), respectively.

Release of 0 -linked glycosaminoglycans was accomplished by treatment with $1 \mathrm{~mol} / 1$ sodium borohydride (Alfa Inorganics, Beverly, Mass, USA) in $0.4 \mathrm{~mol} / 1$ sodium hydroxide at $25^{\circ} \mathrm{C}$ for $24 \mathrm{~h}$, after which they were acidified with $1 \mathrm{~mol} / 1$ acetic acid and passed through a small column of Dowex 50-X4, 200-400 mesh, $\mathrm{H}^{+}$form. The unadsorbed material was lyophilized, and aliquots were taken for determination of the size of the released carbohydrate units by filtration on a $0.6 \times 140 \mathrm{~cm}$ column of Bio-Gel P-10 in $0.2 \mathrm{~mol} / 1 \mathrm{am}-$ monium bicarbonate, $\mathrm{pH} 7.8$, without or with prior treatment with freshly prepared $1 \mathrm{~N}$ nitrous acid [21] to specifically degrade heparan sulfate chains.
Table 1. $\left[{ }^{35}\right.$ S]Sulfate incorporation by normal and diabetic rat hearts during perfusion ${ }^{\mathrm{a}}$

\begin{tabular}{lcclll}
\hline Animal & $\begin{array}{l}\text { Heart } \\
\text { weight }\end{array}$ & $\begin{array}{l}\text { Unlabeled } \\
\text { sulfate } \\
\text { added }\end{array}$ & $\begin{array}{l}\text { Medium free sulfate } \\
\text { concentration and spe- } \\
\text { cific activity }\end{array}$ & $\begin{array}{l}\text { Total } \\
{[55] \text { Sul- }} \\
\text { fate incor- } \\
\text { poration }\end{array}$ \\
& (g) & (mmol/1) & (mmol/1) & $(\mathrm{DPM} \times$ \\
$\left.10^{-9} / \mathrm{mmol}\right)$ & $\begin{array}{l}\mathrm{DPM}) \times \\
\left.10^{-3} / \mathrm{g}\right)\end{array}$ \\
\hline $\mathrm{N}-1$ & 0.93 & 0 & 0.06 & 614 & 356 \\
$\mathrm{D}-1$ & 0.79 & 0 & 0.06 & 536 & 460 \\
$\mathrm{~N}-2$ & 1.49 & 0.2 & 0.16 & 306 & 123 \\
$\mathrm{D}-2$ & 0.87 & 0.2 & 0.20 & 250 & 173 \\
$\mathrm{~N}-3$ & 1.44 & 0.5 & 0.28 & 191 & 104 \\
$\mathrm{D}-3$ & 0.83 & 0.5 & 0.24 & 175 & 100 \\
\hline
\end{tabular}

a Heart perfusion was performed for $1 \mathrm{~h}$ in the presence of $1 \mathrm{mCi}$ of sodium ${ }^{35}$ S]sulfate and the indicated amounts of unlabeled sulfate in $15 \mathrm{ml}$ of medium, after which the radiolabeled tissues were extracted sequentially as described in the Methods section. The body weights of the rats were 315,340 and $340 \mathrm{~g}$ for normal rats (N1-3) and 230, 275 and $215 \mathrm{~g}$ for diabetic rats (D1-3); blood sugar values were 7.6, 9.0 and $8.8 \mathrm{mmol} / 1$ for the normal and $26.8,24.9$ and $36.3 \mathrm{mmol} / 1$ for the diabetic rats. The experiment was performed 6 weeks after alloxan administration. ${ }^{\mathrm{b}}$ Total radioactivity in guanidine extracts

\section{Radioactivity measurements}

Scintillation counting was performed in a Beckman LS-7500 instrument utilizing Ultrafluor or Monofluor (both from National Diagnostics, Somerville, NJ, USA).

For examination of the electrophoretically separated products, the stained gels were soaked in Autofluor (National Diagnostics), dried and exposed to Kodak X-Omat film (Eastman Kodak, Rochester, NY, USA) at $-70^{\circ} \mathrm{C}$. The radioactivity pattern of the labeled extracts observed on the fluorograms were graphed with the use of the gel scanning attachment of the Gilford spectrophotometer (Oberlin, Oh, USA).

\section{Statistical analysis}

Values were expressed as the mean \pm the standard error of the mean; Student's t-test for unpaired samples was utilized to determine statistical significance.

\section{Results}

\section{$\left.{ }^{35} S\right]$ sulfate incorporation during heart perfusion}

The perfusion of hearts from normal and alloxan-diabetic rats with $\left[{ }^{35} \mathrm{~S}\right] \mathrm{sulfate}$ was performed both in the absence and presence of added sulfate to help detect any effects of differences in tissue sulfate pool sizes. As would be anticipated, the ${ }^{35}$ S]sulfate incorporation decreased as the specific activity of the radiolabel was reduced by the added sulfate (Table 1 ). At each sulfate concentration the measured specific radioactivities of the normal and diabetic media were approximately equal, and sulfate incorporation into the macromolec- 
Table 2. In vivo $\left[{ }^{35}\right.$ S]sulfate incorporation into guanidine-soluble macromolecules of normal and diabetic rat tissues

\begin{tabular}{|c|c|c|c|c|c|c|c|c|}
\hline Animal $^{\mathfrak{a}}$ & $\begin{array}{l}\text { Time } \\
\text { (h) }\end{array}$ & Heart & Kidney & Liver & Lung & Muscle & Testes & Skin \\
\hline Normal & 4 & $\begin{array}{r}53 \\
\pm 6\end{array}$ & $\begin{array}{r}439 \\
\pm 47\end{array}$ & $\begin{array}{r}334 \\
\pm 67\end{array}$ & $\begin{array}{r}344 \\
\pm 131\end{array}$ & $\begin{array}{r}23 \\
\pm 4\end{array}$ & $\begin{array}{r}49 \\
\pm 2\end{array}$ & $\begin{array}{r}194 \\
\pm \quad 9\end{array}$ \\
\hline Diabetic & 4 & $\begin{array}{r}25 \\
\pm 2\end{array}$ & $\begin{array}{r}184 \\
\pm 11\end{array}$ & $\begin{array}{r}125 \\
\pm 6\end{array}$ & $\begin{array}{r}185 \\
\pm \quad 87\end{array}$ & $\begin{array}{r}13 \\
\pm 3\end{array}$ & $\begin{array}{r}36 \\
\pm 4\end{array}$ & $\begin{array}{r}95 \\
\pm 13\end{array}$ \\
\hline Normal & 24 & $\begin{array}{r}53 \\
\pm 2\end{array}$ & $\begin{array}{r}285 \\
\pm 51\end{array}$ & $\begin{array}{r}74 \\
\pm 18\end{array}$ & $\begin{array}{r}216 \\
\pm \quad 70\end{array}$ & $\begin{array}{r}31 \\
\pm 9\end{array}$ & $\begin{array}{r}46 \\
\pm 3\end{array}$ & $\begin{array}{r}91 \\
\pm 21\end{array}$ \\
\hline Diabetic & 24 & $\begin{array}{r}20 \\
\pm 5\end{array}$ & $\begin{array}{r}80 \\
+22\end{array}$ & $\begin{array}{r}23 \\
\pm \quad 6\end{array}$ & $\begin{array}{r}57 \\
\pm \quad 12\end{array}$ & $\begin{array}{r}10 \\
\pm 1\end{array}$ & $\begin{array}{r}22 \\
\pm 7\end{array}$ & $\begin{array}{r}38 \\
\pm \quad 2\end{array}$ \\
\hline (Diabetic/normal) & & $(0.38)$ & $(0.28)$ & $(0.31)$ & $(0.26)$ & $(0.32)$ & $(0.48)$ & $(0.42)$ \\
\hline
\end{tabular}

a Age-matched normal rats (average body weight $296 \mathrm{~g}$, blood sugar $8.4 \mathrm{mmol} / \mathrm{l}$ ) and 6-week diabetic rats (average body weight $220 \mathrm{~g}$ and blood sugar $30.2 \mathrm{mmol} / 1$ ) received $1.0 \mathrm{mCi}$ of sodium $\left.{ }^{35} \mathrm{~S}\right]$ sulfate intraperitoneally either $4 \mathrm{~h}$ or $24 \mathrm{~h}$ prior to killing. The guanidine extracts represented the following percentages of total sulfate incorporation into macromolecular products of both normal and diabetic tissues: heart, 58 ; kidney, 60; liver, 63; lung, 77; muscle, 62; testes, 22; and skin, 67. Values are expressed as means \pm SEM. For the $4 \mathrm{~h}$ experiments, hearts and kidneys were obtained from 5 normal and 5 diabetic rats; the other tissues came from 3 rats of each type. Two normal and 2 diabetic rats were studied at $24 \mathrm{~h}$

NORMAL
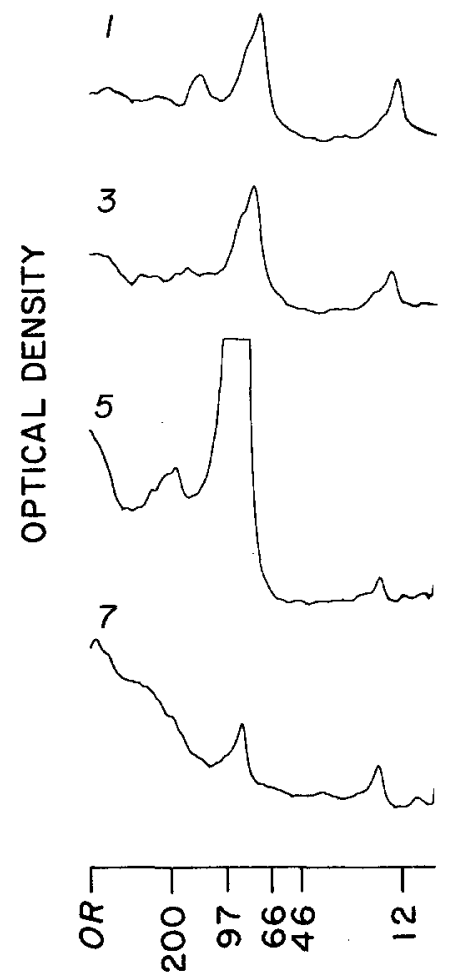

DIABETIC
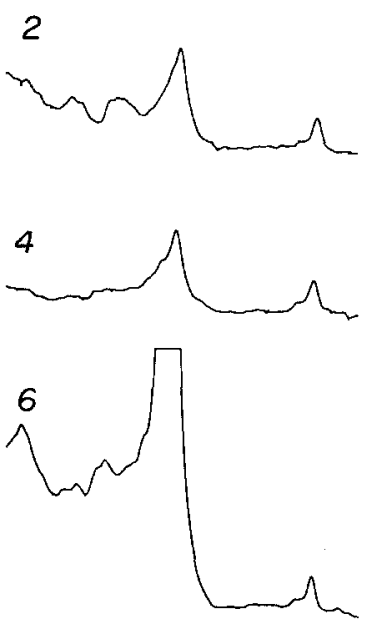

8
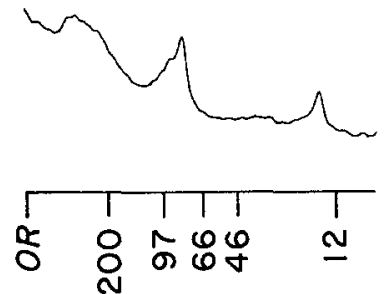

Fig. 1. Densitometric scans obtained after fluorography of SDSpolyacrylamide gel electrophoresis of ${ }^{35}$ S]sulfate-labeled components in normal and diabetic heart extracts after perfusion for $1 \mathrm{~h}$ with $1 \mathrm{mCi}$ of sodium $\left[{ }^{35} \mathrm{~S}\right]$ sulfate. The extracts and the $\mathrm{g}$ of original tissue represented were: $\mathrm{NaCl}, 0.055 \mathrm{~g}$ (scans 1 and 2); $\mathrm{KCl}, 0.16 \mathrm{~g}$ (scans 3 and 4); guanidine hydrochloride, $0.055 \mathrm{~g}$ (scans 5 and 6); SDS-2-mercaptoethanol, $0.35 \mathrm{~g}$ (scans 7 and 8 )

ular constituents of the diabetic hearts was the same or slightly elevated compared to normal. SDS-polyacrylamide gel electrophoresis of the several extracts pre-

pared from normal and diabetic hearts showed similar patterns (Fig.1), with the major portion of incorporated radiolabel being recovered in the guanidine-soluble fraction and being represented predominantly by a component with an apparent molecular weight of 85,000 daltons (Fig. 1). Minor higher molecular weight bands were also observed in the extracts.

\section{In vivo $\left[{ }^{35}\right.$ S]sulfate incorporation in normal and diabetic rats}

For most of the tissues studied, a large portion of the labeled molecules ( 50 to $80 \%$ of the total) were solubilized by guanidine hydrochloride, which would be expected to extract proteoglycans; another 10 to $30 \%$, which would represent sulfated glycoproteins and glycolipids as well as cell surface proteoglycans, was present in the Triton extract. The testes proved the exception, with $65 \%$ of the incorporated sulfate label occurring in the Triton-solubilized fraction and only $22 \%$ being extracted by guanidine hydrochloride.

The SDS-gel electrophoresis of the guanidine extracts of all of the tissues revealed broad bands typical of proteoglycans (data not shown); in the case of the in vivo labeled normal and diabetic hearts the patterns were similar to those shown in Figure 1 for perfused hearts, with the $M_{r}=85,000$ component again being the major sulfate-labeled band. The total amount of radioactivity incorporated into the diabetic animals, however, was much less, as is shown for the guanidine extracts of heart and other tissues in Table 2. The level of radioactivity present decreased between 4 and $24 \mathrm{~h}$, with the decline for the alloxan-diabetic animal appearing to be somewhat greater.

In order to explore the reasons for the marked difference in sulfate incorporation into the diabetic tis- 


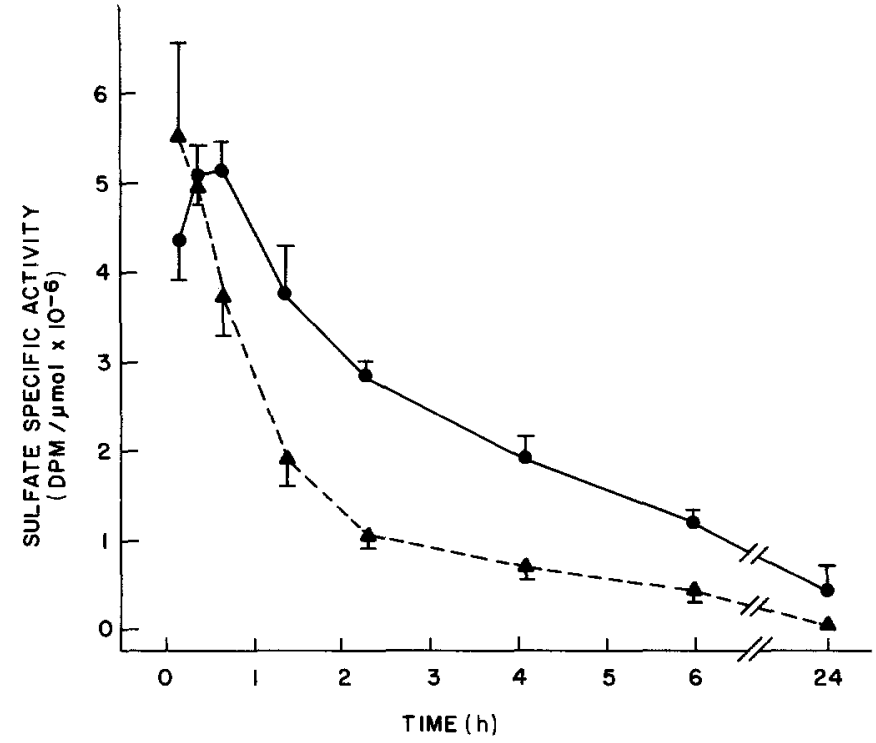

Fig. 2 Serum $\left[{ }^{35}\right.$ S]sulfate specific activity curves of normal $(\bullet)$ and diabetic $(\Delta)$ rats after intraperitoneal injection of $1 \mathrm{mCi}$ of sodium $\left[{ }^{35}\right.$ S]sulfate; 5 normal and 5 diabetic animals were studied. Statistical analysis yielded $p$ values for the comparison of normal and diabetic specific activities of $<0.05$ at $45 \mathrm{~min}$ and $6 \mathrm{~h} ;<0.02$ at $1.4 \mathrm{~h}$ and $<0.01$ at 2.3 and $4.1 \mathrm{~h}$. The ratios of the areas under the curves (diabetic/normal) were 0.61 at $4 \mathrm{~h}(p=<0.005)$ and 0.45 at $24 \mathrm{~h}$

Table 3. Serum sulfate concentration of normal and diabetic rats ${ }^{a}$

\begin{tabular}{lllll}
\hline & Diabetic & Normal & $\begin{array}{l}\text { Diabetic/ } \\
\text { normal }\end{array}$ & $p$ value \\
\hline $\begin{array}{c}\text { Serum sulfate } \\
\text { (mmol/1) }\end{array}$ & $1.23 \pm 0.07$ & $1.67 \pm 0.15$ & 0.74 & $<0.01$ \\
$\begin{array}{c}\text { Serum glucose } \\
(\mathrm{mmol} / \mathrm{l})\end{array}$ & $29.1 \pm 0.11$ & $7.4 \pm 0.24$ & 3.9 & $<0.001$ \\
\hline
\end{tabular}

a The diabetic rats were studied 4 to 6 weeks after alloxan administration, with no apparent effect of the length of diabetes on the serum sulfate level; diabetic rats, $n=19$; age-matched control rats, $n=24$. Average body weight normal rats, $324 \mathrm{~g}$; diabetic rats, $227 \mathrm{~g}$

Table 4. Sulfate content and specific activity of normal and diabetic rat tissues ${ }^{\mathrm{a}}$

\begin{tabular}{|c|c|c|c|c|}
\hline \multirow[t]{2}{*}{ Tissue } & \multicolumn{2}{|l|}{ Normal } & \multicolumn{2}{|l|}{ Diabetic } \\
\hline & $(\mu \mathrm{mol} / \mathrm{g})$ & $\begin{array}{l}\left(\mathrm{DPM} \times 10^{-3} /\right. \\
\mu \mathrm{mol})\end{array}$ & $(\mu \mathrm{mol} / \mathrm{g})$ & $\begin{array}{l}\left(\mathrm{DPM} \times 10^{-3} /\right. \\
\mu \mathrm{mol})\end{array}$ \\
\hline Heart & $0.41 \pm 0.05$ & 463 & $0.36 \pm 0.06$ & 132 \\
\hline Kidney & $0.84 \pm 0.15$ & 945 & $0.97 \pm 0.30$ & 473 \\
\hline Liver & $0.63 \pm 0.12$ & 1,157 & $1.0 \pm 0.23$ & 303 \\
\hline Lung & $0.37 \pm 0.05$ & 1,163 & $0.45 \pm 0.06$ & 728 \\
\hline Muscle & $0.35 \pm 0.05$ & 505 & $0.38 \pm 0.09$ & 237 \\
\hline Testes & $0.32 \pm 0.05$ & 1,708 & $0.31 \pm 0.07$ & 730 \\
\hline Skin & $1.2 \pm 0.35$ & 831 & $1.8 \pm 0.01$ & 233 \\
\hline
\end{tabular}

a The sulfate contents and specific activities were determined on the Tris-acetate extract of the tissues as described in the Methods section, and represent data derived from 5 normal and 5 diabetic rats; average body weights and blood sugars were $273 \mathrm{~g}$ and $8.55 \mathrm{mmol} / \mathrm{I}$ for the normal and $197 \mathrm{~g}$ and $27.5 \mathrm{mmol} / 1$ for the diabetic rats. The specific activities given are those determined at $4 \mathrm{~h}$ after sulfate injection sues in vivo as compared with the heart during perfusion, serum and tissue sulfate specific activities were measured. When serum inorganic sulfate concentration was compared in a large group of diabetic and normal animals, a statistically significant decrease $(p<0.01)$ was found in the diabetic animals (Table 3). In the injected radiolabel, although approximately the same peak level was reached in both normal and diabetic serum (Fig.2), the radioactivity disappeared much more rapidly from the diabetic animals with the result that the area under this curve from time 0 to $4 \mathrm{~h}$ was only 0.61 that of normal $(p<0.005)$, while for time 0 to $24 \mathrm{~h}$ the ratio was 0.45 . The serum specific activities of normal and diabetic animals were significantly different $(p<0.05)$ for all but the 10 and $20 \mathrm{~min}$ and $24 \mathrm{~h} \mathrm{sam-}$ ples (Fig. 2); the ratio of diabetic to normal serum specific activity at $4 \mathrm{~h}$ was 0.38 and at $24 \mathrm{~h}, 0.05$.

The amount of free ${ }^{35}$ S]sulfate present in the tissue fluids was also substantially reduced in the alloxandiabetic rat while the total amounts of sulfate determined chemically were similar or, in the case of liver and skin, actually elevated (Table 4). The sulfate specific activity at $4 \mathrm{~h}$ (Table 4 ) for the diabetic tissues averaged 0.40 that of normal and the 24-h ratio was 0.27 .

Measurement of the renal sulfate clearance for the two types of animals showed a dramatic increase for the alloxan-diabetic rat, with the ratio of diabetic to normal clearance being 3.4 (Table 5).

\section{Characterization of radiolabeled products in normal and diabetic tissues}

Anion-exchange chromatography on DE-52 cellulose of the guanidine hydrochloride-solubilized constituents of heart and kidney indicated that the radiolabeled products formed in both tissues after in vivo $\left[{ }^{35}\right.$ S]sulfate administration were to a large extent

Table 5. Renal clearance of inorganic sulfate in normal and alloxan diabetic rats

\begin{tabular}{llll}
\hline Animal & $\begin{array}{l}\text { Body weight } \\
(\mathrm{g})\end{array}$ & $\begin{array}{l}\text { Blood sugar } \\
(\mathrm{mmol} / \mathrm{l})\end{array}$ & $\begin{array}{l}\text { Sulfate clearance } \\
\left(\mathrm{ml} \cdot \mathrm{min}^{-1} \cdot \mathrm{kg}^{-1}\right)\end{array}$ \\
\hline $\mathrm{N}-1$ & 338 & 9.4 & 1.22 \\
$\mathrm{~N}-2$ & 358 & 8.4 & 1.20 \\
$\mathrm{~N}-3$ & 369 & 7.1 & 1.29 \\
Mean \pm SEM & $355 \pm 9.1$ & $8.3 \pm 0.7$ & $1.24 \pm 0.03$ \\
$\mathrm{D}-1$ & 251 & 33.8 & 6.30 \\
$\mathrm{D}-2$ & 288 & 34.4 & 3.09 \\
$\mathrm{D}-3$ & 198 & 28.8 & 4.72 \\
D-4 & 334 & 28.4 & 2.72 \\
Mean \pm SEM & $268 \pm 29$ & $31.4 \pm 1.6$ & $4.21 \pm 0.82$ \\
$p$ value & $<0.05$ & $<0.01$ & $<0.02$ \\
\hline
\end{tabular}

Normal and diabetic rats were injected intraperitoneally with $200 \mu \mathrm{Ci}$ of sodium $\left[{ }^{35} \mathrm{~S}\right]$ sulfate in $0.5 \mathrm{ml}$ sterile isotonic saline. The animals were placed in metabolism cages and their urine collected for $6 \mathrm{~h}$. Blood samples were taken at 15 and $30 \mathrm{~min}, 1,2$ and $6 \mathrm{~h}$. Renal sulfate clearance was calculated from the average $\mathrm{dpm} / 1$ of the serum and the total radioactivity recovered in the urine 


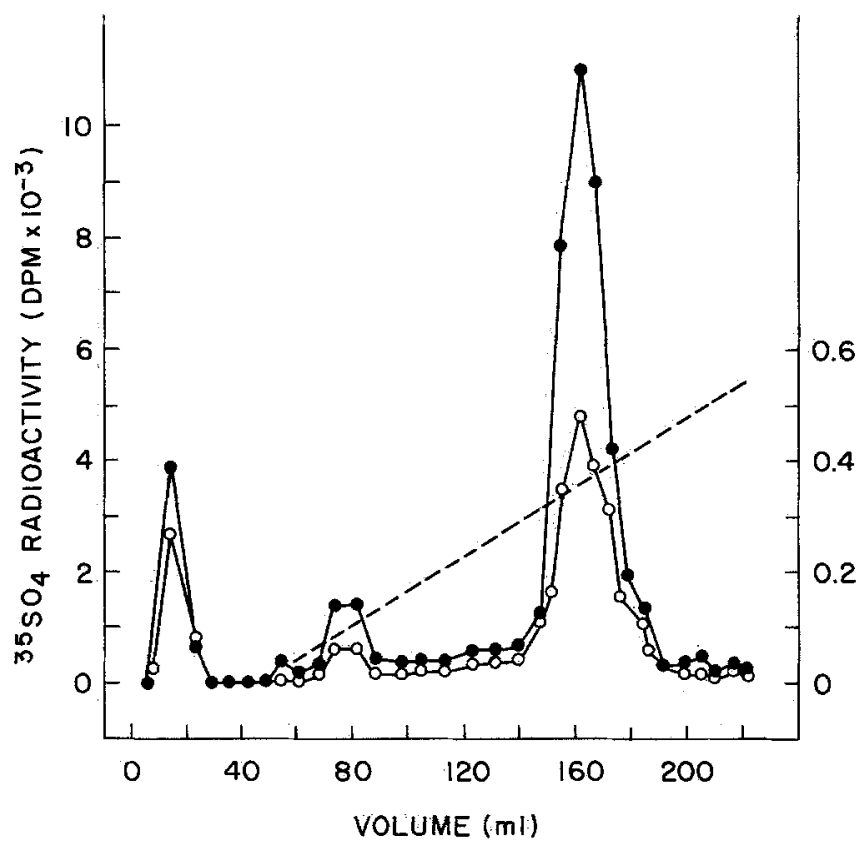

Fig.3. Anion exchange chromatography on DE-52 of the dialyzed guanidine extracts from normal $(1.7 \mathrm{~g}, 0)$ and diabetic $(1.5 \mathrm{~g}, 0)$ hearts obtained from 3 normal and 3 diabetic rats, each of which had received $1 \mathrm{mCi}$ of sodium: $\left[{ }^{35}\right.$ S]sulfate $4 \mathrm{~h}$ prior to killing. The description of the gradient is given in the Materials and methods and the $\mathrm{NaCl}$ concentration is shown by the dashed line

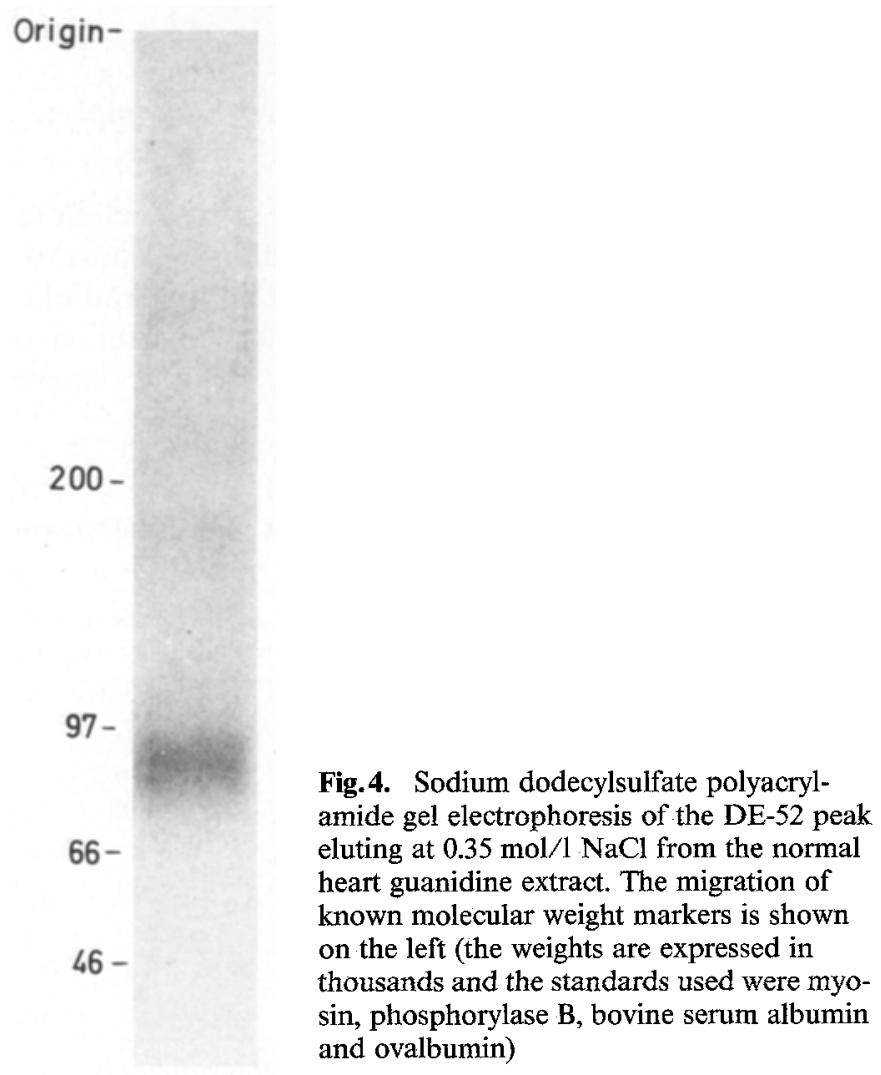

strongly anionic, suggesting its incorporation into proteoglycans. In the heart extracts, the main component emerged at a sodium chloride concentration of

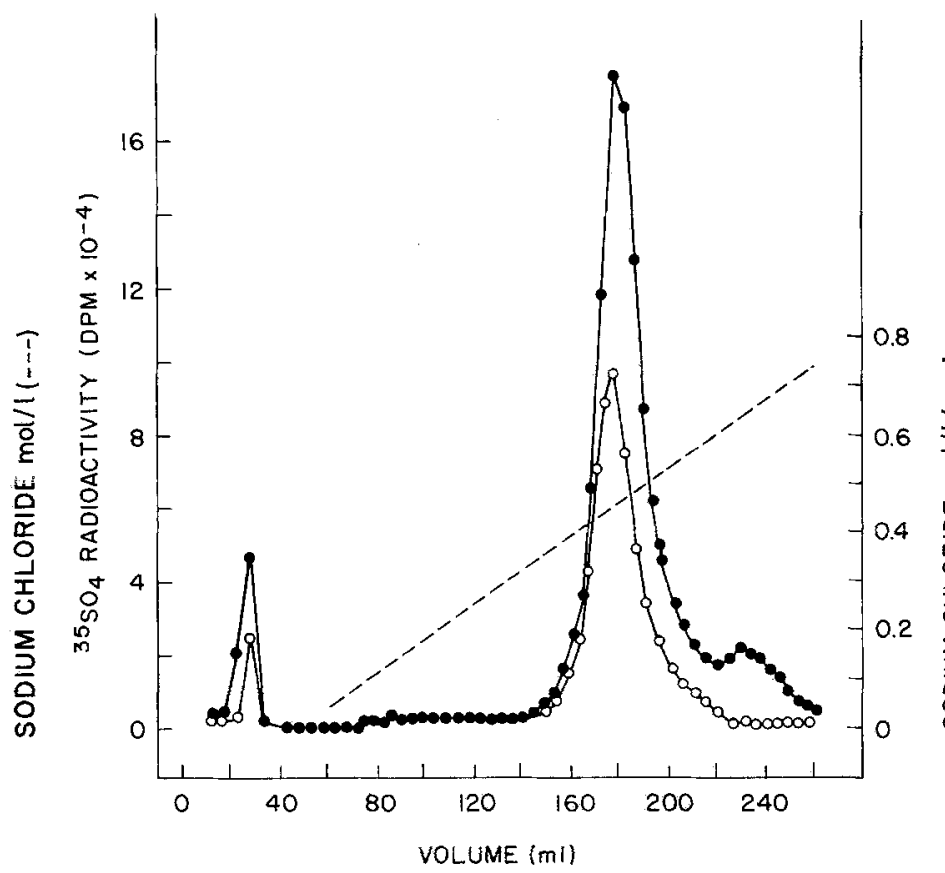

Fig.5. Anion exchange chromatography of normal and diabetic kidney guanidine extracts on DE-52. The pooled normal kidney (O) represented $4.7 \mathrm{~g}$ of original tissue and the diabetic kidney (O) $5.9 \mathrm{~g}$; $(--), \mathrm{NaCl}$ concentration

$0.35 \mathrm{~mol} / 1$ (Fig.3). Gel electrophoretic examination of the material in this peak (Fig. 4) showed the prominent $\mathrm{M}_{\mathrm{r}}=85,000$ band and the two faint higher molecular weight components $\left(M_{r}=360,000\right.$ and 170,000$)$ detected in the original guanidine extract. The smaller amount of radioactivity observed upon DE-52 chromatography of the diabetic components is consistent with the smaller amount of total radioactivity found in the extract, as shown in Table 2. The major guanidine soluble products of both alloxan-diabetic and normal kidneys emerged from the DE-52 column at a salt concentration of $0.5 \mathrm{~mol} / 1$ (Fig. 6).

To evaluate the nature of the sulfated carbohydrate units present in these radiolabeled products, the dialyzed guanidine extracts from diabetic and normal heart, kidney, liver and lung were subjected to pronase digestion followed by Bio-Gel P-30 filtration. The elution profiles from these columns were similar for all of the tissues, with the sulfate radioactivity emerging at the void volume of the column (data not shown), indicating high molecular weight glycopeptides which would be consistent with the presence of peptidelinked glydosaminoglycan chains; since no small molecular weight components were observed, tyrosine sulfate did not appear to be an important labeled constituent in these extracts. No difference was detected in the elution patterns of diabetic and normal tissues.

After alkaline borohydride treatment of the glycopeptides from these four tissues, an approach employed to effect the release of 0-linked glycosaminoglycan 


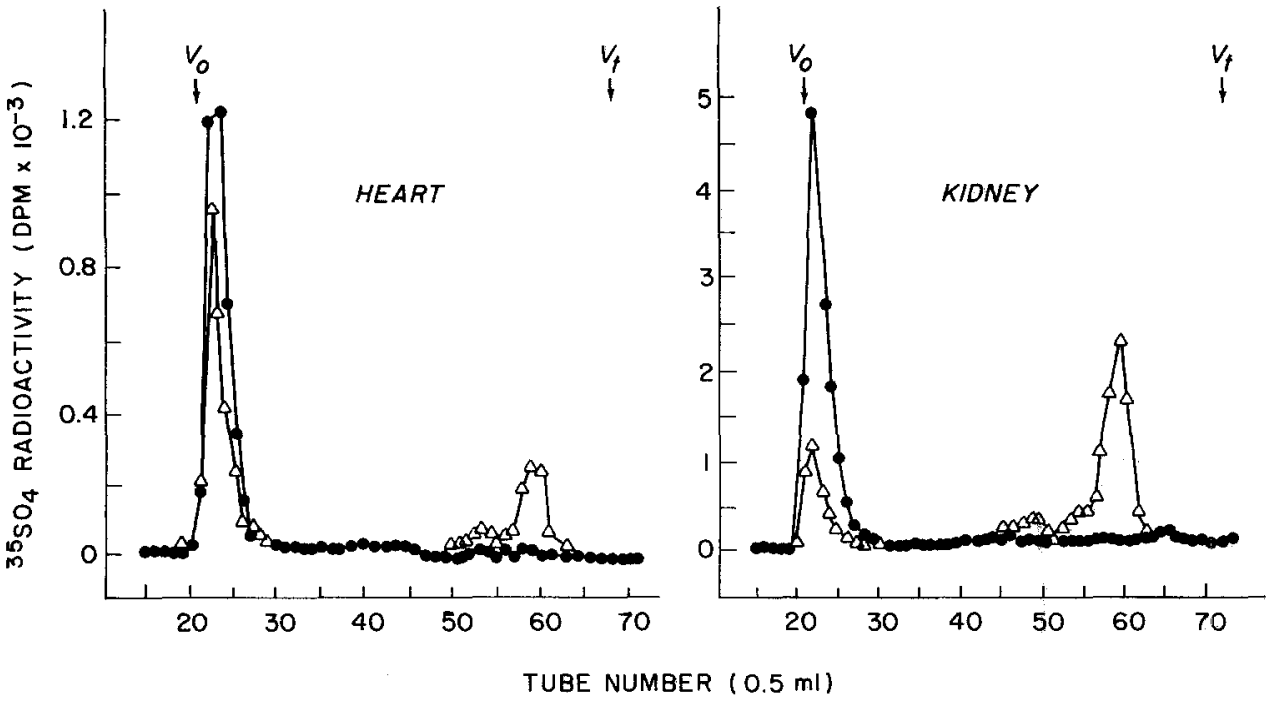

Fig. 6. Bio-Gel P-10 filtration of alkaline borohydride-released glycosaminoglycan chains from normal heart and kidney guanidine extracts before $(0)$ and after $(\Delta)$ nitrous acid treatment; details of the alkaline borohydride and nitrous acid treatments are given in the Materials and methods. The void volume $\left(\mathrm{V}_{\mathrm{o}}\right)$ was determined with the use of Blue Dextran and the total volume $\left(V_{t}\right)$ with $\left[{ }^{3} \mathrm{H}\right]$ mannose chains of the proteoglycans, Bio-Gel P-10 filtration was performed. Sharp peaks at the void volume of the column accounted for all of the radioactivity, as shown in Figure 6 for the normal heart and kidney (similar patterns were obtained for the diabetic heart and kidney), consistent with the presence in each tissue of large glycosaminoglycan chains.

However, after nitrous acid treatment which specifically degrades heparan sulfate, different patterns were seen for heart and kidney. In the heart (Fig. 6), the percentage of sulfate radioactivity contributed by heparan sulfate chains was approximately $20 \%$, as determined from the decrease in the high molecular weight peak after nitrous acid treatment and the appearance of small molecular weight components, which would represent free sulfate and sulfate containing di- and oligosaccharides. In contrast, the kidney (Fig.6) showed a more substantial shift from large to small components, indicating that heparan sulfate represented approximately $70 \%$ of the total guanidine-extracted radioactivity, as would be expected from the large amount of basement membrane in this tissue with its predominance of heparan sulfate. The percentage of heparan sulfate in diabetic heart and kidney was the same as in the normal animals (data not shown).

\section{Discussion}

In order to understand the marked difference in $\left[{ }^{35} \mathrm{~S}\right]$ sulfate incorporation into heart macromolecules observed in the present study when in vivo radioisotope administration was employed rather than heart perfusion, the effect of diabetes on blood and tissue inorganic sulfate was evaluated. The analyses presented show significant differences in sulfate concentration in serum, in the rate of removal of the radioisotope from the blood, and in the rate of renal sulfate clearance. Moreover, although tissue levels of inorganic sulfate were normal or somewhat elevated, the amount of radiolabelled free sulfate present in the tissues was substantially reduced. In the rat, as in other species, sulfate is cleared primarily by urinary excretion; maintenance of serum sulfate levels appears to occur largely through tubular reabsorption [22-24]. Since the uptake of this ion by the tubules, similar to that of phosphate, has been found to be depressed by glucose [23-26], the increased glucose excretion encountered in diabetic animals would be expected to interfere with sulfate homeostasis. Although inorganic sulfate levels in diabetes have not been studied previously, phosphate handling has received attention, and it has been known for some time that an inverse relationship exists between blood glucose and blood phosphate [25]. Indeed, direct interference by glucose with tubular phosphate reabsorption has been proposed on the basis of the finding that urinary phosphate excretion decreased together with glycosuria after institution of optimal control of diabetic patients [26]. It seems reasonable, therefore, to assume that the decreased serum sulfate level observed in the present investigation, together with the very rapid removal of radiolabeled sulfate from the blood after in vivo administration and the enhanced renal clearance of sulfate, is a function of the glycosuria of the diabetic animals. This conclusion is supported by the demonstration that the tissue sulfate radioactivity is also lower in the diabetic animals, excluding the possibility that increased tissue uptake could account for the loss of isotope from the serum. The elevated concentrations of sulfate in some tissues (notably liver and skin) may reflect the increased protein breakdown associated with uncontrolled diabetes, leading to the liberation of sulfur amino acids which are the primary precursors for endogenously produced sulfate.

The importance of measuring and taking into account serum specific activities in studies dealing with diabetic animals has been noted previously for glucose [27] as well as for proline [28]. In the present study, 
Table 6. Correction of diabetic in vivo ${ }^{35}$ S]sulfate incorporation data for serum specific activity differences

\begin{tabular}{|c|c|c|c|c|c|c|c|}
\hline \multirow[t]{2}{*}{ Animal } & Heart & Kidney & Liver & Lung & Muscle & Testes & Skin \\
\hline & \multicolumn{7}{|c|}{$\left(\mathrm{DPM} \times 10^{-3} / \mathrm{g}\right.$ tissue $)$} \\
\hline Normala $^{\mathrm{a}}$ & 53 & 439 & 334 & 344 & 23 & 49 & 194 \\
\hline $\begin{array}{l}\text { Diabetic, } \\
\text { (corrected) }^{\mathrm{b}}\end{array}$ & 47 & 348 & 205 & 303 & 22 & 58 & 154 \\
\hline $\begin{array}{l}\text { Diabetic/ } \\
\text { normal }\end{array}$ & 0.89 & 0.79 & 0.61 & 0.88 & 0.96 & 1.18 & 0.79 \\
\hline
\end{tabular}

a The normal values for the guanidine extracts obtained after $4 \mathrm{~h}$ of in vivo ${ }^{35}$ S]sulfate incorporation are derived from Table 2.

${ }^{b}$ Correction for all but the heart and kidney was based on a diabetic/normal ratio of 0.61 for the areas under the specific activity curves from 0 to $4 \mathrm{~h}$; the heart and kidney corrections were based on a ratio of 0.53 for the same period which was obtained from the curves of the 5 normal and 5 diabetic rats used for these tissues. There was no statistical significance to the differences between normal and diabetic sulfate incorporation after this correction

when corrections were made on the basis of the ratio of the area under normal and diabetic serum specific activity curves, values considerably closer to normal were obtained (Table 6); the average for the diabetic tissues was 0.87 that of the normal, with the differences showing no statistical significance.

These adjusted values may still represent underestimations of sulfate incorporation. If corrections were made using the ratios of the individual tissue specific activities at a single time $(4 \mathrm{~h})$, higher than normal incorporation was obtained for most tissues, with the average of the diabetic values being 1.34 that of the normal. It therefore seems likely that most or all of the reduced incorporation observed in the diabetic tissues can be explained by the much lower serum and tissue sulfate specific activity; the most appropriate data to permit correction of the diabetic values would be specific activity curves for the tissues similar to that obtained for the blood. Perfusion studies therefore have a distinct advantage for comparisons of normal and diabetic tissues, since precursor specific activities can be controlled.

Previous studies dealing with sulfate incorporation in diabetes have seldom taken into account the possibility of differences in precursor specific activity. In vivo studies which reported decreased glycosaminoglycan formation in diabetes in skin [29] and aorta [30,31] failed to measure sulfate specific activity either in tissues or serum; in an investigation dealing with the effect of diabetes on proteoglycan synthesis in cartilage and bone, no correction was made for tissue sulfate radioactivity, despite observed decreases in trichloroacetic acid-soluble radioactivity of 20 and $70 \%$ in cartilage and bone, respectively [32]. However, since this manuscript was completed Klein et al. [33] showed a pronounced decrease in serum sulfate specific activity in rats with streptozotocin-induced diabetes similar to that described in the present report for alloxan-diabetic rats, and indicated that reduced $\left[{ }^{35}\right.$ S]sulfate incorporation into glomerular basement membrane proteoglycans in vivo can be explained by this reduced availabil- ity of radiolabeled precursor. These findings are in contrast to the small sulfate specific activity differences observed in an earlier study from these same investigators [34], as well as in a report by Cohen and Surma [35]. Of particular interest was the observation by Klein et al. [33] that specific activity differences may also occur in vitro, since isolated diabetic glomeruli incubated with labeled sulfate showed a reduced incorporation of radioactivity into proteoglycans compared to normal glomeruli only in the absence of carrier but not when the incubations were carried out in the presence of $0.1 \mathrm{mmol} / 1$ unlabelled sulfate [33]. A dilution of labeled precursor by unequal pools of endogenous sulfate in normal and diabetic tissues may also explain the decreased incorporation of radioactivity observed by Kanwar et al. [35] during perfusion of normal and diabetic rat kidneys with high specific activity sulfate in the absence of any unlabeled material.

In attempting to relate the apparently unaltered myocardial proteoglycan production observed in the present study with the extracellular matrix changes which have been observed in diabetic hearts, it is relevant to consider whether the production of these molecules is the factor determining their deposition and long-term retention in the tissue. Studies with in vivo $\left[{ }^{35}\right.$ S]sulfate-labeled kidney glycosaminoglycans have indicated that, while most of the radioactivity is lost by three days, some labeled molecules persist for at least two weeks [36]. The proteoglycans which are integrated on a long-term basis into the extracellular matrix may therefore represent a small portion of the total synthesized, and their retention may be governed by interaction with other matrix constituents which themselves could be altered in diabetes. In the abnormal glomerular basement membrane of diabetic humans, for which decreased levels of heparan sulfate proteoglycan have been demonstrated, chemical and immunochemical techniques were employed [7]; since the very low myocardial proteoglycan levels make their chemical measurement difficult, a comparison of the concentration of these compounds in normal and diabetic hearts would be facilitated by antibodies to purified heart proteoglycans. Previous studies of myocardial proteoglycans have been limited to the identification of the glycosaminoglycans chains present in the tissue, which include in addition to heparan sulfate, hyaluronic acid, chondroitin sulfate and dermatan sulfate [37]. In the present investigation, intact rat myocardial proteoglycans have been characterized by anion exchange chromatography and electrophoresis; of particular interest is the observation that of the three bands seen by SDSpolycrylamide electrophoresis under reducing conditions, most of the label is present in a relatively small molecular weight component $\left(\mathrm{M}_{\mathrm{r}}=85,000\right)$. Further purification of these molecules is currently under way in our laboratory to permit antibody production and to determine the relationship of the various glycosaminoglycans to the three observed proteoglycans. 
Since the basement membrane changes which have been observed in kidney include not only the decrease in heparan sulfate proteoglycan but also a substantial increase in the amount of Type IV collagen deposition [7-10], it will be important to evaluate whether this collagen, which represents a minor component of normal myocardium, is elevated in the diabetic heart or whether other types of carbohydrate-rich collagen or structural glycoproteins are responsible for the increased periodic acid-Schiff material observed in this tissue in diabetes.

Acknowledgements. The author would like to acknowledge the excellent technical assistance of Ms. K. M. Gorski and Mr. T.Crowley. This work was supported by Grant HL 31315 from the National Institutes of Health.

\section{References}

1. Rubler S, Dlugash J, Yuceoglu YZ, Kumral T, Branwood AW, Grishman A (1972) New type of cardiomyopathy associated with diabetic glomerulosclerosis. Am J Cardiol 30: 595-602

2. Hamby RI, Zoneraich S, Sherman L (1974) Diabetic cardiomyopathy. J Am Med Assoc 229: 1749-1754

3. Regan TJ, Lyons MM, Ahmed SS, Levinson GE, Oldewurtel HA, Ahmad MR, Haider B (1977) Evidence for cardiomyopathy in familial diabetes mellitus. J Clin Invest 60: 885-899

4. Ledet T, Gotzsche O, Heickendorff L (1984) The pathology of diabetic cardiopathy: pathogenetic reflections. In: J.Jarret (ed) Diabetes and heart disease, Elsevier, Amsterdam

5. Brown DM, Andres GA, Hostetter TH, Mauer SM, Price R, Venkatachalam MA (1982) Kidney complications. Diabetes 31 [Suppl 1]: 71-81

6. Sternberg M, Cohen-Forterre L, Peyroux J (1985) Connective tissue in diabetes mellitus: biochemical alterations of the intercellular matrix with special reference to proteoglycans, collagens and basement membranes. Diabete Metab 11: 27-50

7. Parthasarathy N, Spiro RG (1982) Effect of diabetes on the glycosaminoglycan component of the human glomerular basement membrane. Diabetes 31: 738-741

8. Shimomura H, Spiro RG (1987) Studies on the macromolecular components of the human glomerular basement membrane, alterations in diabetes: decreased levels of heparan sulfate proteoglycan and laminin. Diabetes 36: 374-381

9. Beisswenger PJ, Spiro RG (1973) Studies on the human glomerular basement membrane. Composition, nature of the carbohydrate units, changes in diabetes mellitus. Diabetes 22: 180-193

10. Klein L, Butcher DL, Sudilovsky O, Kikkawa R, Miller M (1975) Quantification of collagen in renal glomeruli isolated from human nondiabetic and diabetic kidneys. Diabetes 24: 1057-1065

11. Rohrbach DH, Hassell JR, Kleinman HK, Martin GR (1982) Alterations in basement membrane (heparan sulfate) proteoglycan in diabetic mice. Diabetes 31:185-188

12. Kanwar YS, Farquhar MG (1979) Anionic sites in the glomerular basement membrane. In vivo and in vitro localization to the laminae rarae by cationic probes. J Cell Biol 81: 137-153

13. Frank JS, Langer GA (1974) The myocardial interstitium: its structure and its role in ionic exchange. J Cell Biol 60: 586-601

14. Fein FS, Strobeck JE, Malhotra A, Scheuer J, Sonnenblick EH (1981) Reversibility of diabetic cardiomyopathy with insulin in rats. Circ Res 49: 1251-1261

15. Fischer VW, Leskiw ML, Barner HD (1981) Myocardial structure and capillary basal laminar thickness in experimentally diabetic rats. Exp Mol Pathol 35: 244-256

16. Baandrup U, Ledet $T$, Rasch R (1981) Experimental diabetic cardiopathy preventable by insulin treatment. Lab Invest 45 : 169-173

17. Neely JR, Rovetto MJ (1975) Techniques for perfusing isolated rat hearts. Methods Enzymol 39:43-60
18. Eagle $H$ (1959) Amino acid metabolism in mammalian cell cultures. Science 130: 432-437

19. Spencer B (1960) The ultramicro determination of inorganic sulphate. Biochem J 75: 435-440

20. Laemmli UK (1970) Cleavage of structural proteins during assembly of bacteriophage $T_{4}$. Nature [Lond] 227: 680-685

21. Shively JE, Conrad HE (1976) Formation of anhydrosugars in the chemical depolymerization of heparin. Biochemistry 15: 3932-3942

22. Lin JH, Levy G (1983) Renal clearance of inorganic sulfate in rats: effect of acetaminophen-induced depletion of endogenous sulfate. J Pharm Sci 72: 213-217

23. Cohen JJ, Berglund F, Lotspeich WD (1957) Interrelations during renal tubular reabsorption in the dog among several anions showing a sensitivity to glucose and phlorizin. Am J Physiol 189: 331-338

24. Cohen JJ, Berglund F, Lotspeich WD (1956) Renal tubular reabsorption of acetoacetate, inorganic sulfate and inorganic phosphate in the dog as affected by glucose and phlorizin. Am J Physiol 184: 91-96

25. Izzo JL (1956) Interrelationships of glucose and inorganic phosphorus in blood and urine of patients with diabetes mellitus. Proc Soc Exp Biol Med 91: 373-377

26. Raskin P, Pak CYC (1981) The effect of chronic insulin therapy on phosphate metabolism in diabetes mellitus. Diabetologia 21: $50-53$

27. Spiro RG (1959) Role of insulin in two pathways of glucose metabolism: in vivo glucosamine and glycogen synthesis. Ann NY Acad Sci 82: 366-373

28. Brownlee $M$ and Spiro RG (1979) Glomerular basement membrane metabolism in the diabetic rat. In vivo studies. Diabetes 28: $121-125$

29. Schiller S, Dorfman A (1957) The metabolism of mucopolysaccharides in animals. IV The influence of insulin. $\mathrm{J}$ Biol Chem 227: $625-632$

30. Ichida T, Kalant N (1968) Aortic glycosaminoglycans in atheroma and alloxan diabetes. Can J Biochem 46: 249-260

31. Cohen MP, Foglia VG (1970) Aortic mucopolysaccharides in experimental diabetes. Diabetes 19: 639-643

32. Nimni ME, Gorn AH, Weiss RE (1981) Abnormalities in the biosynthesis of cartilage and bone proteoglycans in experimental diabetes. Diabetes 30: 670-677

33. Klein DJ, Brown DM, Oemega TR (1986) Glomerular proteoglycans: partial structural characterization and metabolism of de novo synthesized heparan- ${ }^{35} \mathrm{SO}_{4}$ and dermatan ${ }^{35} \mathrm{SO}_{4}$ proteoglycans in streptozotocin-induced diabetic rats. Diabetes 35: $1130-1142$

34. Brown DM, Klein DJ, Michael AF, Oemega TR (1982) ${ }^{35} \mathrm{~S}-\mathrm{gly}-$ cosaminoglycan and ${ }^{35}$ S-glycopeptide metabolism by diabetic glomeruli and aorta. Diabetes 31: 418-425

35. Cohen MP, Surma ML (1984) Effect of diabetes on in vivo metabolism of $\left[{ }^{35} \mathrm{~S}\right]-$ labeled glomerular basement membrane. Diabetes 33: 8-12

36. Kanwar YS, Rosenzweig LJ, Linker A and Jakubowski ML (1983) Decreased de novo synthesis of glomerular proteoglycans in diabetes: biochemical and autoradiographic evidence. Proc Natl Acad Sci USA 80: 2272-2275

37. Barry DN, Bowness JM (1975) Identification and turnover of glycosaminoglycans in rat kidneys. Can J Biochem 53: 713-720

38. Ohishi H, Binette JP, Schmid K (1986) Myocardial chondroitin sulfates $D$ and $E$ in a case of acute carbon monoxide poisoning. Clin Chim Acta 156: 157-164

Received: 17 November 1986

and in revised form: 3 March 1987

Dr. Mary Jane Spiro

Elliott P. Joslin Research Laboratories

One Joslin Place

Boston, MA 02215

USA 